\title{
Risk factor of pneumonitis on dose-volume relationship for chemoradiotherapy with durvalumab: Multi-institutional research in Japan
}

\author{
Yoshiko Oshiro $^{\mathrm{a}, \mathrm{b}, *}$, Masashi Mizumoto ${ }^{\mathrm{b}, \mathrm{h}}$, Yuta Sekino ${ }^{\mathrm{b}, \mathrm{c}}$, Kazushi Maruo ${ }^{\mathrm{d}}$, Toshiki Ishida ${ }^{\mathrm{b}, \mathrm{e}}$, \\ Taisuke Sumiya $^{\text {b,f }}$, Masatoshi Nakamura ${ }^{b}$, Ayako Ohkawa ${ }^{g}$, Daichi Takizawa ${ }^{i}$, Toshiyuki Okumura ${ }^{\text {b,j }}$, \\ Yoshio Tamaki ${ }^{\text {b,e }}$, Hideyuki Sakurai ${ }^{\mathrm{b}}$ \\ a Department of Radiation Oncology, Tsukuba Medical Center Hospital, Ibaraki, Japan \\ ${ }^{\mathrm{b}}$ Department of Radiation Oncology, University of Tsukuba, Ibaraki, Japan \\ ${ }^{\mathrm{C}}$ Department of Radiation Oncology, Tsuchiura Kyodo General Hospital, Ibaraki, Japan \\ ${ }^{\mathrm{d}}$ Department of Biostatistics, Faculty of Medicine, University of Tsukuba, Ibaraki, Japan \\ e Department of Radiation Oncology, Ibaraki Prefectural Central Hospital, Ibaraki, Japan \\ ${ }^{\mathrm{f}}$ Department of Radiation Oncology, Mito Kyodo General Hospital, Ibaraki, Japan \\ ${ }^{\mathrm{g}}$ Department of Radiation Oncology, Mito Medical Center Hospital, Ibaraki, Japan \\ h Department of Radiation Oncology, Ibarakihigashi National Hospital, Ibaraki Japan \\ ${ }^{\mathrm{i}}$ Department of Radiation Oncology, Hitachi General Hospital, Ibaraki, Japan \\ ${ }^{\mathrm{j}}$ Department of Radiation Oncology, Ibaraki Seinan Medical Center Hospital, Ibaraki, Japan
}

\section{A R T I C L E I N F O}

\section{Article history:}

Received 19 February 2021

Revised 13 May 2021

Accepted 24 May 2021

Available online 29 May 2021

\section{Keywords:}

Radiotherapy

Durvalumab

Pneumonitis

Dose-volume histogram

Proton therapy

\begin{abstract}
A B S T R A C T
Objectives: To estimate appropriate dose-volume parameters for avoidance of pneumonitis in use of chemoradiotherapy and durvalumab for treatment of lung cancer.

Materials and methods: Patients with non-small cell lung cancer treated with concurrent chemoradiotherapy followed by durvalumab at 9 centers were enrolled in the study. Three-dimensional radiotherapy, intensity modulated radiotherapy, and proton beam therapy were used. The frequency and severity of pneumonitis and the dose-volume relationship for normal lung were evaluated. Univariable and multivariable analyses were conducted to identify risk factors. A covariate adjusted hazard ratio was then estimated for the percentages of normal lung volume irradiated at $\geq X \mathrm{~Gy}(\mathrm{Vx})(\mathrm{X}=5-40)$ and lung volume non-irradiated at $\geq X$ Gy $(X=5-40)$, with the covariates selected in the variable selection. Cumulative incidence functions and covariate adjusted hazard ratios were also estimated for dichotomized variables, with estimated cut-off points.

Results: A total of 91 patients were enrolled in the study. The median time from the start of radiotherapy to development of pneumonitis was 4.1 months. Pneumonitis was observed in 80 patients (88\%), including grade 2 or severe pneumonitis in 31 (34\%) and $\geq$ grade 3 pneumonitis in 11 (12\%). Pneumonitis was inside the irradiation field in 73 of the 80 patients (91\%). The selected factors for $\geq$ grade 2 pneumonitis were $\mathrm{V}_{20}$, and primary site (upper lobe) in multivariable analysis. The cut off value of $\mathrm{V}_{20}$ was $18.99 \%$, and there was a significant difference between $V_{20}$ of $<18.77$ and $\geq 18.77$.

Conclusion: Though there are some limitation of this study, the basic concept of concurrent chemoradiotherapy with an emphasis on $\mathrm{V}_{20}$ remains unchanged in use of durvalumab. However, we recommend reduction of $\mathrm{V}_{20}$ to as small a value as possible in use of this therapy.

(C) 2021 The Author(s). Published by Elsevier B.V. on behalf of European Society for Radiotherapy and

Oncology. This is an open access article under the CC BY-NC-ND license (http://creativecommons.org/
\end{abstract} licenses/by-nc-nd/4.0/).
* Corresponding author at: University of Tsukuba, Amakubo 2-1-1, Tukuba, Ibaraki, Japan.

E-mail address: ooyoshiko@pmrc.tsukuba.ac.jp (Y. Oshiro).

\section{Introduction}

With recent progress of immune therapy, the indication for immune checkpoint inhibitors (ICIs) has expanded in cancer treatment. In 2017, the efficacy of durvalumab after concurrent chemoradiotherapy (CCRT) was suggested in the phase III PACIFIC 
study [1-2], and this approach is now widely used as a standard therapy for unresectable locally advanced non-small cell lung cancer (NSCLC). However, an ICI has a risk of an autoimmune response, including interstitial pneumonitis, and this raises a concern about an increased risk of radiation pneumonitis with use of durvalumab.

The risk of radiation pneumonitis is correlated with various factors, such as combined chemotherapy, radiotherapy, age, poor performance status, smoking history, poor lung function, co-existence lung disease of chronic obstructive pulmonary disease (COPD), interstitial lung disease (ILD), cytokines or biomarker level, and dosimetric factors of radiotherapy [3-9]. In radiotherapy, the dose-volume relationship for the normal lung is one of the most important factors, and this has been evaluated using a dosevolume histogram (DVH) in previous studies of CCRT. The importance of the lung volume irradiated at $\geq 20 \mathrm{~Gy}\left(\mathrm{~V}_{20}\right)$ has been established for radiation pneumonitis [7,10], and parameters such as $\mathrm{V}_{10}, \mathrm{~V}_{30}$, and mean lung dose (MLD) have also been suggested as significant risk factors for radiation pneumonitis [7,10-19]. In the PACIFIC study, the incidence of pneumonitis was infrequent [2]; however, it is unclear if previous dose-volume parameters can be used for radiotherapy with durvalumab. In this study, we evaluated DVHs of patients with locally advanced NSCLC who received CCRT followed by durvalumab at 9 centers, and we analyzed risk factors for pneumonitis.

\section{Material and methods}

\section{Patients}

Patients who received durvalumab following CCRT at 9 centers in Ibaraki prefecture from March 2018 to August 2020 were enrolled in this study. Each institutional review board approved this study. Written informed consent was obtained from all patients before treatment was administrated.

\section{Radiation therapy}

Three-dimensional radiotherapy (3DCRT), intensity modulated radiotherapy (IMRT) including tomotherapy, and proton beam therapy (PBT) were available at the 9 centers, and patients were treated with all these modalities. In PBT, an equivalent dose to photon therapy was used based on a relative biological effectiveness of 1.1 [20]. The target policy differed among the centers and elective nodal irradiation (ENI) was performed at some centers. Respiratory synchronization, breath holding, and abdominal compression were used for respiratory control. Normal lung volume was contoured as the bilateral lung volume minus the clinical target volume (CTV). Lasso-based variable selection with Bayesian information criteria was also performed.

\section{Analysis}

The DVH was calculated on a treatment planning system at each center. Pneumonitis was graded according to CTCAE version 4.0. The end point was defined as the time to occurrence of pneumonitis ( $\geq$ grade 2 or $\geq$ grade 3 ) while treating death as a competing risk. A univariable subdistribution hazard model was used for explanatory variables [21-22] of age ( $\geq 68$ vs. $<68$ ), gender, performance status (PS, 0 or 1 vs. 2 or 3 ), stage (stage II vs. III vs. others), pathology (adenocarcinoma vs. squamous cell carcinoma vs. others), programmed cell death ligand-1 (PDL-1) status, serum value of sialylated carbohydrate antigen (KL-6), smoking history, Brinkman index, presence of COPD, ILD, pulmonary infection, chemotherapy regimen (cisplatin (CDDP) + vinorelbine (VNR) vs. carboplatin (CBDCA) + paclitaxel (PTX) vs. CDDP + pemetrexed
(PEM) vs. CDDP + tegafur, gimeracil, oteracil potassium (TS-1) vs. others), radiotherapy modality (3D-CRT vs. 3DCRT + IMRT vs. IMRT vs. PBT), respiratory control method (synchronization vs. depression vs. abdominal compression vs. none), treatment field (ENI vs. involved field radiation therapy (IFRT), number of treatment fields shrinkage times, total dose, CTV, planning target volume (PTV), MLD, and percentages of normal lung volume irradiated at $\geq X$ Gy $(\mathrm{Vx})(\mathrm{X}=5-40)$ and lung volume not irradiated at $\geq X$ Gy (remnant lung volume, RLVx) $(X=5-40)$.

Lasso-based variable selection based on Bayesian information criteria was conducted using the above candidate explanatory variables to identify risk factors [23-24]. The covariate adjusted hazard ratios (HR) for Vx and RLVx were then estimated using a subdistribution hazard model with the covariates selected in the variable selection. In these analyses, $V x$ and $\operatorname{RLVx}(X=5-40)$ were treated as categorical variables divided into four with estimated quartiles. The following parameters previously reported as significant factors for radiation pneumonitis were also evaluated: $V_{5}(>40 \%$ [15], $>60 \%$ [13]) $\mathrm{V}_{10}\left(>30 \%\right.$ [15], >35\% [15]) $\mathrm{V}_{20}\left(>25 \%\right.$ [7], 35\% [6,11]), $\mathrm{V}_{30}$ (>20\% [15]), and MLD (15 Gy, 18 Gy [11,19]). A cumulative incidence function was also estimated for each level of the above categorized variables. Time-dependent ROC curve analysis [25-26] was then applied for $\operatorname{Vx}$ and $\operatorname{RLVx}(X=5-40)$, and the timedependent AUC and cut-off points that maximized sensitivities and specificities at 6 months from irradiation were estimated. Cumulative incidence functions and covariate adjusted HRs were all estimated for the dichotomized variables with determination of cut-off points. $\mathrm{P}<0.05$ was defined as significant in all statistical tests. R ver. 4.0.3 (R Core Team) and SAS (SAS Institute Inc.) were used for the analyses.

\section{Results}

Patients

The characteristics of the 91 patients enrolled in the study are shown in Table 1 . The cohort included 67 males and 24 females, and the median age was 68 years old (range, 37 to 86 years). Performance status was $0,1,2$, and 3 for $63,22,4$, and 2 cases; the tumor stage was II, IIIA, IIIB, IIIC and IV in 2, 35, 35, 12, and 1 cases, and there was postoperative recurrence in 6 cases. One stage IV case had a small brain metastasis and was treated with stereotactic radiotherapy, after which CCRT followed by durvalumab was indicated. The pathology was adenocarcinoma, squamous cell carcinoma, and others in 34, 37 and 20 cases, respectively.

Of the 74 cases in which PD-L1 was evaluated, the level was < $1 \%, 1-10 \%, 12.5-50 \%, 65-75 \%, 80-90 \%$, and $95-100 \%$ in 15 , $16,25,5,9$, and 4 cases, respectively. KL- 6 was also measured in 74 cases, and the median value was $305 \mathrm{U} / \mathrm{ml}$ (range, 138-2103 $\mathrm{U} / \mathrm{ml}$ ). COPD was present in 27 patients, 5 had ILD, and one patient had mycobacterium intracellulare before the start of CCRT. A total of 82 patients had a smoking history and 26 were current smokers. The median Brinkmann index was 900 (range, 0 to 3300).

A summary of treatment is shown in Table 2. Radiotherapy with 3DRT, IMRT, a combination of 3DRT and IMRT, and PBT was conducted in $67,12,10$ and 2 patients, respectively. The treatment field was ENI in 33 cases and IFRT in 58. The median treatment dose was $60 \mathrm{~Gy}$ (range, 45 to $66 \mathrm{~Gy}$ ). Adaptive radiotherapy was performed and the number of shrunk targets were $0,1,2,3$, and 4 in $3,68,17,2$, and 2 cases, respectively.

The mean follow-up period was 14.8 months (range, 3.1 to 31.5 months) and 81 patients (89\%) were alive at the last follow up. Durvalumab were administered 1-26 times (median, 11 times). At the last follow-up, durvalumab was ongoing in 27 cases, and 23 had completed administration for 1 year. However, durvalumab 
Table 1

Patient characteristics.

\begin{tabular}{|c|c|c|}
\hline Item & & Value \\
\hline \multirow[t]{2}{*}{ Gender } & Male & 67 \\
\hline & Female & 24 \\
\hline \multirow[t]{2}{*}{ Age } & Median & 68 \\
\hline & Range & $37-86$ \\
\hline \multirow[t]{4}{*}{ Performance status } & 0 & 63 \\
\hline & 1 & 22 \\
\hline & 2 & 4 \\
\hline & 3 & 2 \\
\hline \multirow[t]{6}{*}{ TMN Stage } & II & 2 \\
\hline & IIIA & 35 \\
\hline & IIIB & 35 \\
\hline & IIIC & 12 \\
\hline & IV & 1 \\
\hline & Recurrent disease & 6 \\
\hline \multirow[t]{3}{*}{ Pathology } & Adenocarcinoma & 34 \\
\hline & Squamous cell carcinoma & 37 \\
\hline & Others & 20 \\
\hline \multirow[t]{7}{*}{ PDL-1 } & $<1 \%$ & 15 \\
\hline & $1.0-10 \%$ & 16 \\
\hline & $12.5-50 \%$ & 25 \\
\hline & $65-75 \%$ & 5 \\
\hline & $80-90 \%$ & 9 \\
\hline & $95-100 \%$ & 4 \\
\hline & Not measured & 17 \\
\hline \multirow[t]{2}{*}{ KL-6 (U/ml) } & Median & 305 \\
\hline & Range & $138-2103$ \\
\hline \multirow[t]{3}{*}{ Smoking } & Current smoker & 26 \\
\hline & Ex-smoker & 56 \\
\hline & Non smoker & 9 \\
\hline \multirow[t]{2}{*}{ Brinkman index } & Median & 900 \\
\hline & Range & $0-300$ \\
\hline \multirow[t]{3}{*}{ Co-existing lung disease } & ILD & 5 \\
\hline & COPD & 27 \\
\hline & Infection & 1 \\
\hline
\end{tabular}

was interrupted in 41 patients due to disease progression or toxicities.

\section{Pneumonitis}

The median time from the start of therapy to development of pneumonitis was 4.1 months (range, 1.9 to 16.4 months). Pneumonitis developed in 80 cases $(88 \%)$, including grade 2 or severe pneumonitis in 31 (34\%) and $\geq$ grade 3 pneumonitis in $11(12 \%)$. Pneumonitis was inside the irradiation field in 73 of the 80 cases (91\%). In the 7 cases with pneumonitis spreading outside the irradiation field, grade 3 or severer pneumonitis occurred in 5 (grade 1: $2: 3: 4: 5=1: 1: 2: 2: 1$ ) (Table 3).

In univariable analysis, tumor location (upper lobe), ILD, PBT, total dose, $\mathrm{Vx}(\mathrm{x}=10-40)$, and remnant lung dose of $<10 \mathrm{~Gy}$ and 15 Gy were significantly associated with the incidence of $\geq$ grade 2 pneumonitis; and PS, location, chemotherapy (CDDP + VNR vs. CDDP + PEM or others), radiation modality (3DCRT vs. others), respiratory control, PTV, and Vx $(x=10-40)$ were significant factors associated with the incidence of $\geq$ Grade 3 pneumonitis (Table 4 ).

Based on lasso variable selection, $\mathrm{V}_{20}$ and primary site (upper lobe) were selected as the prognostic factors for $\geq$ grade 2 pneumonitis, however no variable was selected for $\geq$ grade 3 pneumonitis. So the primary site was treated as a covariate factors for estimating covariate adjusted HR for $\geq$ grade 2 pneumonitis. The mean $\mathrm{V}_{20}$ was $19.4 \%$ in all patients, and the mean $\mathrm{V}_{20}$ levels by pneumonitis grade were $16.6 \%, 18.5 \%, 21.3 \%, 28.8 \%, 18.3 \%$, and $20 \%$ for grades 0 to 5 , respectively (Table 5 ). The cut-off for $V_{20}$ was estimated as $18.77 \%$ (AUC 0.701 ) and there was a significant difference in the incidence of pneumonitis between $V_{20}$ of $<18.77 \%$ and $\geq 18.77 \%$ (adjusted HR: 2.840, $p=0.015$; Fig. 1 ). Since this cut-off was smaller than in previous studies, the sensitiv-
Table 2

Treatment strategy.

\begin{tabular}{|c|c|}
\hline Item & Value \\
\hline \multicolumn{2}{|l|}{ Chemotherapy Regimen } \\
\hline CDDP + VNR & 23 \\
\hline CBDCA + PTX & 37 \\
\hline CDDP + PEM & 4 \\
\hline $\mathrm{CDDP}+\mathrm{TS}-1$ & 20 \\
\hline Others & 7 \\
\hline \multicolumn{2}{|l|}{ Radiotherapy } \\
\hline 3D-CRT & 67 \\
\hline 3DCRT + IMRT & 10 \\
\hline IMRT & 12 \\
\hline PBT & 2 \\
\hline \multicolumn{2}{|l|}{ Respiratory control } \\
\hline Synchronization & 39 \\
\hline Depression & 16 \\
\hline Abdominal compression & 5 \\
\hline None & 31 \\
\hline \multicolumn{2}{|l|}{ Treatment field } \\
\hline ENI & 33 \\
\hline IFT & 58 \\
\hline \multicolumn{2}{|l|}{ Treatment dose } \\
\hline Median & $60 \mathrm{~Gy}$ \\
\hline 45 Gy & 1 \\
\hline $60 \mathrm{~Gy}$ & 50 \\
\hline 62 Gy & 1 \\
\hline $65.4 \mathrm{~Gy}$ & 1 \\
\hline 66 Gy & 38 \\
\hline \multicolumn{2}{|l|}{$\begin{array}{l}\text { Median Clinical Target Volume (CTV) } \\
\quad \text { (cc) }\end{array}$} \\
\hline Total & $193.2(13.1-896.1)$ \\
\hline 3DCRT & $184.0(13.1-878.9)$ \\
\hline 3DCRT + IMRT & $262.4(27.9-896.1)$ \\
\hline IMRT & $227.0(51.5-607.0)$ \\
\hline PBT & $68.9(57.2-80.6)$ \\
\hline \multicolumn{2}{|l|}{ Planning Target Volume (PTV) (cc) } \\
\hline Total & $351.6(68.7-1241.4)$ \\
\hline 3DCRT & $346.0(68.7-1241.4)$ \\
\hline 3DCRT + IMRT & $460.5(157.6-1219.2)$ \\
\hline IMRT & $347.1(189.7-660.0)$ \\
\hline PBT & $351.6(68.7-1241.4)$ \\
\hline \multicolumn{2}{|l|}{ Number of field shrinkage } \\
\hline None & 3 \\
\hline Once & 68 \\
\hline Twice & 17 \\
\hline Third & 2 \\
\hline Fourth & 2 \\
\hline
\end{tabular}

ity and specificity were calculated for $\mathrm{V}_{20}=20 \%, 25 \%, 30 \%$, and $35 \%$. The sensitivity was reduced and specificity was enhanced as the cut-off value increased (Fig. 2). The cut-off values for $\mathrm{Vx}(\mathrm{x}=5-$ 40 ) are shown in Fig. 3. The AUCs were all $>0.7$, indicating that they were relatively reliable.

Among previously suggested parameters, $\mathrm{V}_{10}>30 \%(\mathrm{p}=0.037$ for $\geq$ grade 2$),>35 \%(p=0.017$ for $\geq$ grade 3$) V_{20}>25 \%$ ( $\mathrm{p}=0.026$ for $\geq$ grade 3 ), $30 \%(\mathrm{p}=0.011$ and 0.009 for $\geq$ grade 2 and 3 ), and $35 \%$ ( $<<0.001$ for $\geq$ grade 2 ), and MLD $>15$ Gy ( $p=0.017$ for $\geq$ grade 2$)$ and $18 \mathrm{~Gy}(\mathrm{p}=0.003 \mathrm{for} \geq$ grade 3 ) were also significant factors according to cummulative incidence analysis.

\section{Discussion}

In chemoradiotherapy for lung cancer, radiation pneumonitis is one of the most important toxicity. Many parameters have been proposed as significant factors for radiation pneumonitis, with the best known being $V_{20}$. In 1999, Graham et al. found that $V_{20}$ was significantly correlated with the incidence and grade of radiation pneumonitis, and suggested that a treatment plan with $\mathrm{V}_{20}>35 \%$ should not be used because fatal pneumonitis occurred 
Table 3

Outcome of treatment.

\begin{tabular}{|c|c|}
\hline Item & Value \\
\hline \multicolumn{2}{|l|}{ Follow-up time } \\
\hline Median & 14.8 months \\
\hline Range & 3.1-31.5 months \\
\hline \multicolumn{2}{|l|}{ Number of doses of durvalumab } \\
\hline Median & 11 \\
\hline Range & $1-26$ \\
\hline \multicolumn{2}{|l|}{ Status of durvalumab } \\
\hline Complete & 23 \\
\hline Ongoing & 27 \\
\hline Interruption & 41 \\
\hline \multicolumn{2}{|l|}{ Pneumonitis } \\
\hline None (Grade 0) & 11 \\
\hline Grade 1 & 49 \\
\hline Grade 2 & 20 \\
\hline Grade 3 & 6 \\
\hline Grade 4 & 4 \\
\hline Grade 5 & 1 \\
\hline \multicolumn{2}{|l|}{$\begin{array}{l}\text { Time from start of radiotherapy to } \\
\text { pneumonitis }\end{array}$} \\
\hline Median & 4.2 months \\
\hline Range & 1.9 to 16.4 months \\
\hline \multicolumn{2}{|l|}{ Pneumonitis $(\mathrm{N}=80)$} \\
\hline \multicolumn{2}{|l|}{ Symptoms } \\
\hline Symptomatic & 31 \\
\hline Asymptomatic & 49 \\
\hline \multicolumn{2}{|l|}{ Relation to irradiation field } \\
\hline Inside radiation field & 73 \\
\hline Outside radiation field & 7 \\
\hline \multicolumn{2}{|l|}{ Use of steroids } \\
\hline Yes & 54 \\
\hline No & 26 \\
\hline \multicolumn{2}{|l|}{ Maximum dose of steroids } \\
\hline $20-25 \mathrm{mg}$ & 7 \\
\hline $30-35 \mathrm{mg}$ & 5 \\
\hline $40 \mathrm{mg}$ & 4 \\
\hline $60 \mathrm{mg}$ & 2 \\
\hline $80 \mathrm{mg}$ & 2 \\
\hline $125 \mathrm{mg}$ & 1 \\
\hline $1000 \mathrm{mg}$ & 5 \\
\hline
\end{tabular}

in a patient at this $\mathrm{V}_{20}$ value. In this report [10], $42 \%$ of the patients received some form of chemotherapy, and most received concurrent or pre-irradiation chemotherapy with a cisplatin regimen. Then, in 2005, Tsujino et al. reported the significance of $V_{20}$ in CCRT [7]. The incidence and grade of radiation pneumonitis were shown to be significantly related to the $\mathrm{V}_{20}$ value and the incidence of radiation pneumonitis differed significantly between $\mathrm{V}_{20}>25 \%$ and $\leq 25 \%[7]$.

The efficacy of ICIs has subsequently been established in cancer treatment, and durvalumab is now used after CCRT. However, ICIs have off-target effects and toxicities, including interstitial pneumonitis. Thus, there may be an increased risk of pneumonitis due to potential overlapping radiation and chemical pneumonitis in CCRT plus durvalumab for NSCLC. However, criteria for DVH parameters have not been established for this procedure.

Biologically, radiation pneumonitis occurs between 3 weeks up to 6 months after radiation exposure [27]. In our study, the median time from the start of therapy to development of pneumonitis was 4.1 months, and compatible to this report. In our study, $\geq$ grade 2 and $\geq$ grade 3 pneumonitis occurred in $34 \%$ and $12 \%$ of cases, respectively, which are relatively high compared to previous studies. The incidence of $\geq$ grade 3 pneumonitis was $4.5 \%$ in the PACIFIC trial [2], and the incidences of $\geq$ grade 2 and $\geq$ grade 3 pneumonitis were $24 \%(17 / 71)$ and $4.2 \%(3 / 71)$ in the CCRT reported by Tsujino et al. [7]. The reason for the higher incidences in the current study is unclear. Pneumonitis caused by factors other than radiotherapy was also present, including drug induced pneumonitis, and we did not separate this from radiation pneu-
Table 4

Univariate analysis of factors related to pneumonitis.

\begin{tabular}{|c|c|c|}
\hline \multirow[t]{2}{*}{ Factors } & \multicolumn{2}{|c|}{ P-value } \\
\hline & $\begin{array}{l}\geq \text { Grade } \\
2\end{array}$ & $\begin{array}{l}\geq \text { Grade } \\
3\end{array}$ \\
\hline Age ( $\leq 68$ vs. $>68)$ & 0.280 & 0.275 \\
\hline Gender & 0.890 & 0.910 \\
\hline Performance Status (0/1 vs. 2 or 3 ) & 0.313 & $<0.001$ \\
\hline KL-6 & 0.315 & 0.449 \\
\hline Stage (II vs III) & 0.596 & 0.103 \\
\hline Stage (II vs others) & 0.577 & 0.279 \\
\hline $\begin{array}{l}\text { Pathology (adenocarcinoma vs. squamous cell } \\
\text { carcinoma) }\end{array}$ & 0.687 & 0.810 \\
\hline Smoking history (current vs. non-smoker) & 0.737 & 0.662 \\
\hline Smoking history (current vs. ex-smoker) & 0.348 & 0.519 \\
\hline Location (upper lobe vs. other) & 0.007 & 0.025 \\
\hline Brinkman Index & 0.928 & 0.930 \\
\hline COPD & 0.989 & 0.569 \\
\hline ILD & 0.017 & 0.633 \\
\hline Chemotherapy (CDDP + VNR vs. CBDCA + PTX) & 0.679 & 0.654 \\
\hline Chemotherapy (CDDP + VNR vs. CDDP + PEM) & 0.672 & $<0.001$ \\
\hline Chemotherapy (CDDP + VNR vs. TS-1) & 0.676 & 0.343 \\
\hline Chemotherapy (CDDP + VNR vs. others) & 0.244 & $<0.001$ \\
\hline Irradiation modality (3DCRT vs. IMRT) & 0.101 & $<0.001$ \\
\hline Irradiation modality (3DCRT vs. 3DCRT + IMRT) & 0.394 & $<0.001$ \\
\hline Radiation modality (3DCRT vs. PBT) & $<0.001$ & $<0.001$ \\
\hline Respiratory control (None vs. synchronization) & 0.099 & 0.503 \\
\hline Respiratory control (None vs. suppression) & 0.608 & 0.805 \\
\hline $\begin{array}{l}\text { Respiratory control (None vs. abdominal } \\
\text { compression) }\end{array}$ & 0.374 & $<0.001$ \\
\hline Treatment field (ENI vs. IFRT) & 0.711 & 0.491 \\
\hline Total dose & $<0.001$ & 0.847 \\
\hline CTV & 0.310 & 0.072 \\
\hline PTV & 0.289 & 0.018 \\
\hline Target shrinking & 0.283 & 0.543 \\
\hline Mean lung dose & 0.033 & 0.104 \\
\hline $\mathrm{V}_{5}$ & 0.052 & 0.074 \\
\hline $\mathrm{V}_{10}$ & $<0.001$ & 0.002 \\
\hline $\mathrm{V}_{15}$ & $<0.001$ & 0.004 \\
\hline $\mathrm{V}_{20}$ & $<0.001$ & 0.004 \\
\hline $\mathrm{V}_{25}$ & $<0.001$ & 0.008 \\
\hline$V_{30}$ & $<0.001$ & 0.022 \\
\hline$V_{35}$ & $<0.001$ & 0.026 \\
\hline $\mathrm{V}_{40}$ & 0.002 & 0.041 \\
\hline Remnant lung volume (RLV) $<5 \mathrm{~Gy}$ & 0.096 & 0.345 \\
\hline $\mathrm{RLV}<10 \mathrm{~Gy}$ & 0.026 & 0.197 \\
\hline $\mathrm{RLV}<15 \mathrm{~Gy}$ & 0.043 & 0.283 \\
\hline $\mathrm{RLV}<20 \mathrm{~Gy}$ & 0.049 & 0.328 \\
\hline $\mathrm{RLV}<25 \mathrm{~Gy}$ & 0.056 & 0.382 \\
\hline RLV $<30$ Gy & 0.063 & 0.436 \\
\hline $\mathrm{RLV}<35 \mathrm{~Gy}$ & 0.069 & 0.466 \\
\hline $\mathrm{RLV}<40 \mathrm{~Gy}$ & 0.080 & 0.506 \\
\hline
\end{tabular}

Table 5

Incidence of pneumonitis.

\begin{tabular}{ccc}
\hline Pneumonitis grade & $\mathrm{n}$ & Mean $\mathrm{V}_{20} \pm \mathrm{SD}(\%)$ \\
\hline 0 & 11 & $16.6 \pm 9.2$ \\
1 & 49 & $18.5 \pm 5.7$ \\
2 & 20 & $21.3 \pm 5.8$ \\
3 & 6 & $28.8 \pm 5.1$ \\
4 & 4 & $17.8 \pm 1.2$ \\
5 & 1 & 20.0 \\
Total & 91 & $19.4 \pm 7.0$ \\
\hline
\end{tabular}

monitis because it is difficult to distinguish these conditions. However, a certain number of severe pneumonitis that were not dependent on radiotherapy were thought to occur, considering that 5 of the 7 cases of pneumonitis outside the irradiation field was $\geq$ grade 3 , and that the mean $V_{20}$ increased with severity of pneumonitis increased up to grade 3 , but $V_{20}$ in grades 4 and 5 was rather low. The incidences of $\geq$ grade 2 and $\geq$ grade 3 


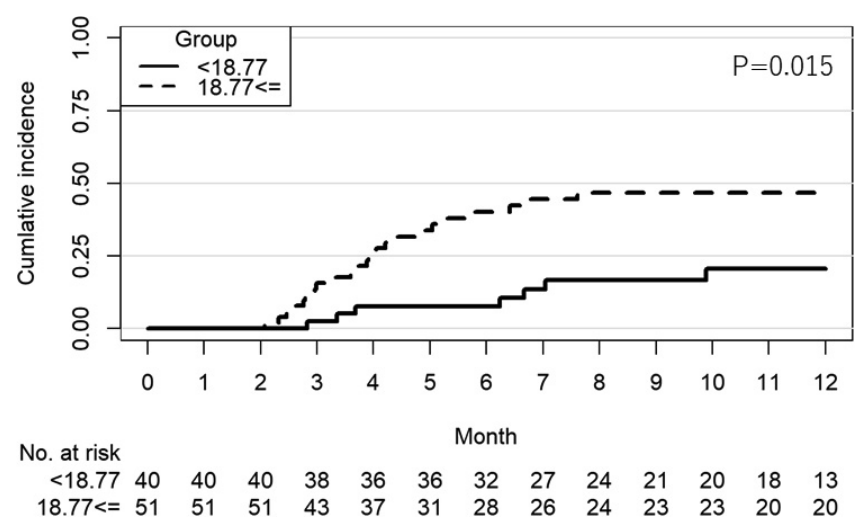

Fig. 1. Cumulative incidence curve for $\geq$ grade 2 pneumonitis stratified by $V_{20}$. in-field pneumonitis were $28 \%$ and $6.5 \%$, respectively, which are similar to those found by Tsujino et al. The high general incidence of pneumonitis may have been due to the lack of strictly defined criteria for administration of steroids due to the retrospective multicenter study design.

In our study, $\mathrm{V}_{20}$ was the only dosimetry factor that was significantly associated with pneumonitis in multivariable analysis. Since the $V_{20}$ cut-off value was $18.77 \%$ for prediction of grade 2 pneumonitis was much lower than previously reported values, we evaluated the sensitivity and specificity for $V_{20}$ values of $20 \%$, $25 \%, 30 \%$, and $35 \%$. The specificity increased, but sensitivity was reduced as this value increased. This suggests that severe pneumonitis that is not related to radiotherapy occurs with a constant probability. Other previously suggested criteria, including $\mathrm{V}_{10}$ of $30 \%$ and 35\%, and MLD of $10 \mathrm{~Gy}, 15 \mathrm{~Gy}$, and $18 \mathrm{~Gy}$, were significant
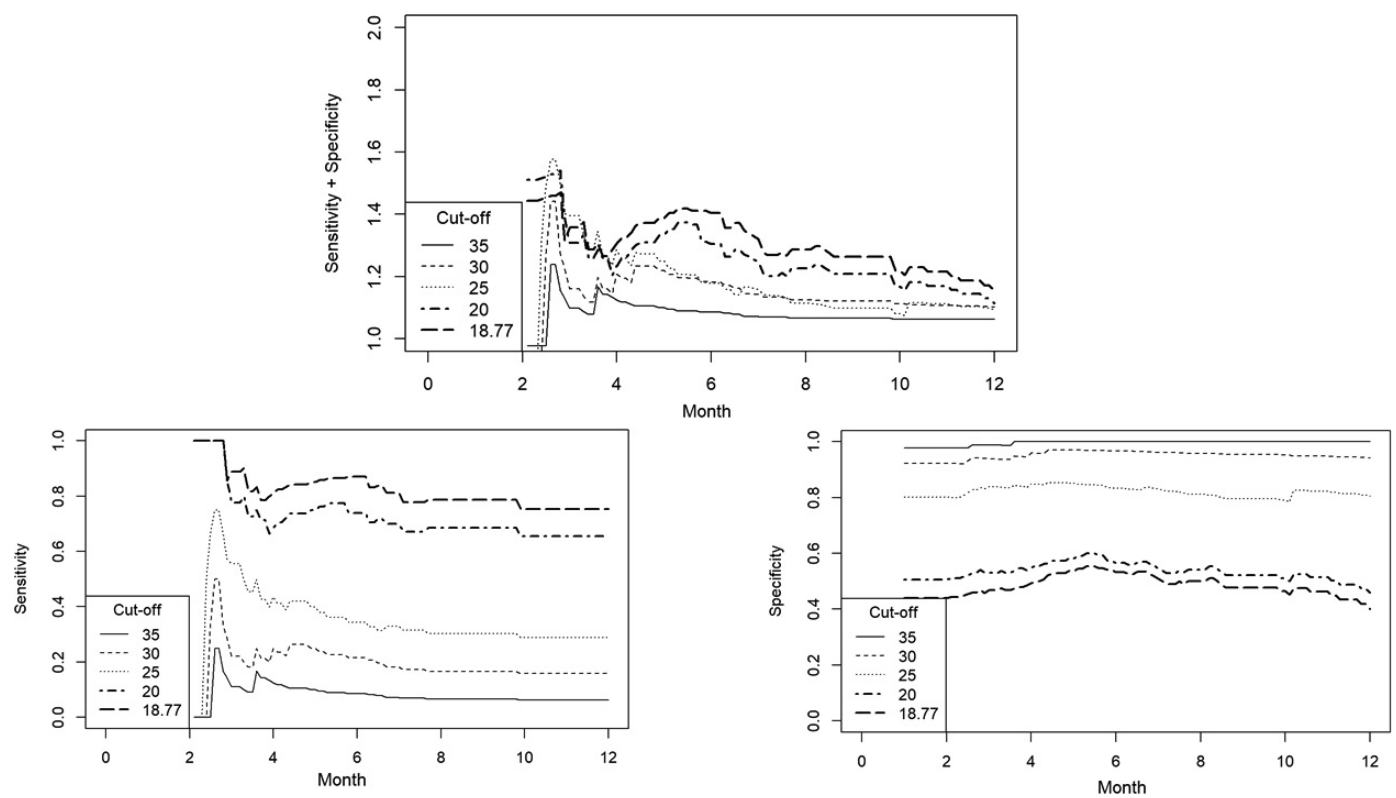

Fig. 2. Sensitivity and specificity for $\mathrm{V}_{20}=20 \%, 25 \%, 30 \%$, and $35 \%$.

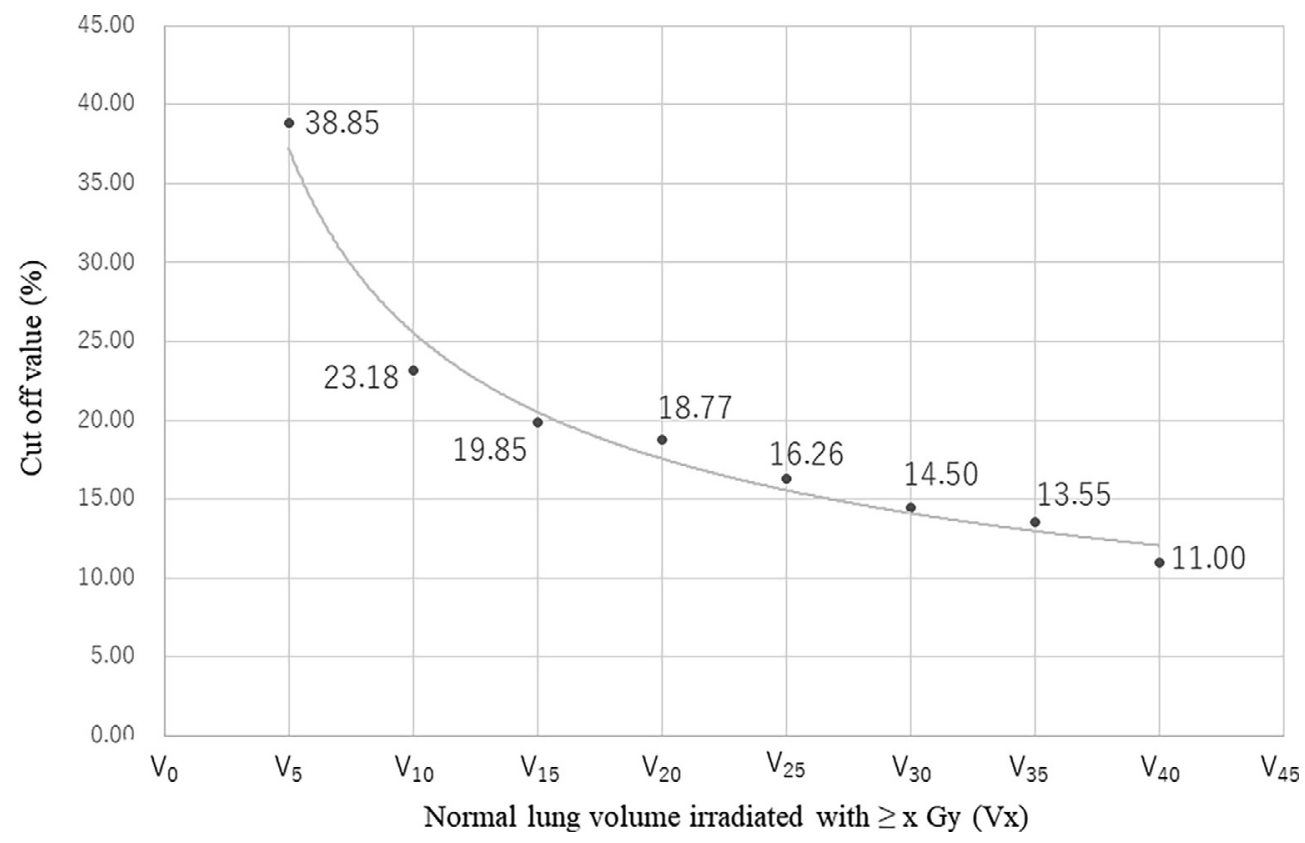

Fig. 3. Cut-off values for $\mathrm{Vx}(\mathrm{x}=5-40)$. 
factors for pneumonitis in univariate analysis; however, these factors are closely correlated with $\mathrm{V}_{20}$.

There are some limitations of the study, including the retrospective design, short follow up period, and absence of a defined policy to evaluate pneumontis. The severity of pneumonitis was followed by CTCAE, but diagnosed by each pulmonologist or radiation oncologist. Therefore, the classification of grades 2 and 3 pneumonitis may be ambiguous. Also, in clinical practice, it is difficult to keep $V_{20}$ at $<19 \%$ for bulky NSCLC. Within these limitations, we conclude that the basic concept of radiotherapy with emphasis on $V_{20}$ is unchanged in CCRT followed by durvalumab, but that an effort to reduce $V_{20}$ with any modality should be made in use of this therapy.

\section{Declaration of Competing Interest}

The authors declare that they have no known competing financial interests or personal relationships that could have appeared to influence the work reported in this paper.

\section{Acknowledgement}

This work was supported by University of Tsukuba.

\section{References}

[1] Antonia SJ, Villegas A, Daniel D, Vicente D, Murakami S, Hui R, et al. Overall survival with durvalumab after chemoradiotherapy in stage III NSCLC. N Engl J Med 2018;379(24):2342-50.

[2] Antonia SJ, Villegas A, Daniel D, Vicente D, Murakami S, Hui R, et al. Durvalumab after chemoradiotherapy in stage III non-small-cell lung cancer. N Engl J Med 2017;377(20):1919-29.

[3] Kong F-M, Wang S. Nondosimetric risk factors for radiation-induced lung toxicity. Semin Radiat Oncol 2015;25(2):100-9.

[4] Zhang X-J, Sun J-G, Sun J, Ming H, Wang X-X, Wu L, et al. Prediction of radiation pneumonitis in lung cancer patients: a systematic review. J Cancer Res Clin Oncol 2012;138(12):2103-16.

[5] Mehta V. Radiation pneumonitis and pulmonary fibrosis in non-small-cell lung cancer: pulmonary function, prediction, and prevention. Int J Radiat Oncol Biol Phys 2005;63(1):5-24.

[6] Jeremic B, Hennig M, Zimmermann FB. Predictors of radiation pneumonitis after radiotherapy in lung cancer. Int J Radiat Oncol Biol Phys 2005;61(1):302.

[7] Tsujino K, Hirota S, Endo M, Obayashi K, Kotani Y, Satouchi M, et al. Predictive value of dose-volume histogram parameters for predicting radiation pneumonitis after concurrent chemoradiation for lung cancer. Int J Radiat Oncol Biol Phys 2003;55(1):110-5.

[8] Stenmark MH, Cai X-W, Shedden K, Hayman JA, Yuan S, Ritter T, et al. Combining physical and biologic parameters to predict radiation-induced lung toxicity in patients with non-small-cell lung cancer treated with definitive radiation therapy. Int J Radiat Oncol Biol Phys 2012;84(2):e217-22.
[9] Arroyo-Hernandez M, Maldonado F, Lozano-Ruiz F, Munoz-Montano W, Nunez-Baez M, Arrieta O. Radiation-induced lung injury: current evidence. BMC Pulm Med 2021;21(1):9.

[10] Graham MV, Purdy JA, Emami B, Harms W, Bosch W, Lockett MA, et al. Clinical dose-volume histogram analysis for pneumonitis after 3D treatment for nonsmall cell lung cancer (NSCLC). Int J Radiat Oncol Biol Phys 1999;45(2):323-9.

[11] Barriger RB, Fakiris AJ, Hanna N, Yu M, Mantravadi P, McGarry RC. Dosevolume analysis of radiation pneumonitis in non-small-cell lung cancer patients treated with concurrent cisplatinum and etoposide with or without consolidation docetaxel. Int J Radiat Oncol Biol Phys 2010;78(5):1381-6.

[12] Fay M, Tan A, Fisher R, Mac Manus M, Wirth A, Ball D. Dose-volume histogram analysis as predictor of radiation pneumonitis in primary lung cancer patients treated with radiotherapy. Int J Radiat Oncol Biol Phys 2005;61(5):1355-63.

[13] Jo I-Y, Kay C-S, Kim J-Y, Son S-H, Kang Y-N, Jung J-Y, et al. Significance of lowdose radiation distribution in development of radiation pneumonitis after helical-tomotherapy-based hypofractionated radiotherapy for pulmonary metastases. J Radiat Res 2014;55(1):105-12.

[14] Kim TH, Cho KH, Pyo HR, Lee JS, Zo JI, Lee DH, et al. Dose-volumetric parameters for predicting severe radiation pneumonitis after threedimensional conformal radiation therapy for lung cancer. Radiology $2005 ; 235(1): 208-15$.

[15] Kobayashi H, Uno T, Isobe K, Ueno N, Watanabe M, Harada R, et al. Radiation pneumonitis following twice-daily radiotherapy with concurrent carboplatin and paclitaxel in patients with stage III non-small-cell lung cancer. Jpn J Clin Oncol 2010;40(5):464-9.

[16] Kong F-M, Hayman JA, Griffith KA, Kalemkerian GP, Arenberg D, Lyons S, et al. Final toxicity results of a radiation-dose escalation study in patients with nonsmall-cell lung cancer (NSCLC): predictors for radiation pneumonitis and fibrosis. Int J Radiat Oncol Biol Phys 2006;65(4):1075-86.

[17] Kwa SLS, Lebesque JV, Theuws JCM, Marks LB, Munley MT, Bentel G, et al. Radiation pneumonitis as a function of mean lung dose: an analysis of pooled data of 540 patients. Int J Radiat Oncol Biol Phys 1998;42(1):1-9.

[18] Piotrowski T, Matecka-Nowak M, Milecki P. Prediction of radiation pneumonitis: dose-volume histogram analysis in 62 patients with non-small cell lung cancer after three-dimensional conformal radiotherapy. Neoplasma 2005;52(1):56-62.

[19] Ramella S, Trodella L, Mineo TC, Pompeo E, Stimato G, Gaudino D, et al. Adding ipsilateral V20 and V30 to conventional dosimetric constraints predicts radiation pneumonitis in stage IIIA-B NSCLC treated with combinedmodality therapy. Int J Radiat Oncol Biol Phys 2010:76(1):110-5.

[20] Paganetti H, Niemierko A, Ancukiewicz M, Gerweck LE, Goitein M, Loeffler JS, et al. Relative biological effectiveness (RBE) values for proton beam therapy. Int J Radiat Oncol Biol Phys 2002;53(2):407-21.

[21] Fine JP, Gray RJ. A proportional hazards model for the subdistribution of a competing risk. J Am Stat Assoc 1999;94(446):496-509.

[22] Gray G. Subdistribution Analysis of Competing Risks. R package version 2.2-10. 2020. https://CRAN.R-project.org/package $=$ cmprsk.

[23] Fu Z, Parikh CR, Zhou B. Penalized variable selection in competing risks regression. Lifetime Data Anal 2017;23(3):353-76.

[24] Fu Z. Penalized Variable Selection in Competing Risks Regression. R package version 1.0. 2015. https://CRAN.R-project.org/package=crrp.

[25] Blanche P. Time-Dependent ROC Curve and AUC for Censored Survival Data. R package version 0.4. 2019. https://CRAN.R-project.org/package=timeROC.

[26] Blanche P, Dartigues JF, Jacqmin-Gadda H. Estimating and comparing timedependent areas under receiver operating characteristic curves for censored event times with competing risks. Stat Med 2013;32(30):5381-97.

[27] Morgan GW, Pharm B, Breit SN. Radiation and the lung: a reevaluation of the mechanisms mediating pulmonary injury. Int J Radiat Oncol Biol Phys 1995;31 (2):361-9. 